This item was submitted to Loughborough's Research Repository by the author.

Items in Figshare are protected by copyright, with all rights reserved, unless otherwise indicated.

\title{
Psychological support for sport coaches: An exploration of practitioner psychologist perspectives
}

PLEASE CITE THE PUBLISHED VERSION

https://doi.org/10.1080/02640414.2018.1423854

\section{PUBLISHER}

(C) Taylor \& Francis

\section{VERSION}

AM (Accepted Manuscript)

\section{PUBLISHER STATEMENT}

This work is made available according to the conditions of the Creative Commons Attribution-NonCommercialNoDerivatives 4.0 International (CC BY-NC-ND 4.0) licence. Full details of this licence are available at: https://creativecommons.org/licenses/by-nc-nd/4.0/

\section{LICENCE}

CC BY-NC-ND 4.0

\section{REPOSITORY RECORD}

Kelly, Sarah, Richard C. Thelwell, Jamie Barker, and Chris G. Harwood. 2019. "Psychological Support for Sport Coaches: An Exploration of Practitioner Psychologist Perspectives". figshare. https://hdl.handle.net/2134/28216. 
PSYCHOLOGICAL SUPPORT TO COACHES

$12{ }^{1}$ Centre for Sport, Health, and Exercise Research, Sport and Exercise, Staffordshire

13 University, Stoke-on-Trent, UK; ${ }^{2}$ Sport and Exercise Science, University of

14 Portsmouth, UK; ${ }^{3}$ School of Sport, Exercise, and Health Sciences, Loughborough

15 University, UK.

Psychologist Perspectives.

\author{
Sarah Kelly ${ }^{1}$ \\ Richard Thelwell ${ }^{2}$ \\ Jamie B. Barker ${ }^{1}$ \\ Chris G. Harwood ${ }^{3}$ \\ Submitted: August 2017
}

9

Psychological Support for Sport Coaches: An Exploration of Practitioner 
PSYCHOLOGICAL SUPPORT TO COACHES

1 Psychological Support for Sport Coaches: An Exploration of Practitioner 
PSYCHOLOGICAL SUPPORT TO COACHES

Abstract

2 In the present study we add to the literature by exploring the degree to which UK

3 practitioner psychologists perceive themselves able to support sport coaches, and how

4 professional training prepares psychologists for coach work across performance

5 domains. Ten participants comprising seven sport and exercise psychologists with

6 Health Care Professions Council (HCPC) practitioner psychologist status and three

7 trainee psychologists studying towards the British Psychological Society (BPS)

8 qualification in sport and exercise psychology (QSEP) were individually interviewed.

9 All participants reported prior experience of working with coaches across all

10 performance domains. We explored: practitioner's understanding of the challenges

11 coaches face within their job; practitioner's experiences of coach work; perspectives

12 about the ways in which practitioners could and should support coaches; and, the degree

13 to which professional training prepares practitioners for coach work. Using

14 recommended procedures of Connelly and Peltzer (2016), content analysis revealed

15 practitioners perceived the challenges faced by coaches are different at grassroots level

16 compared to those working with elite athletes, and that practitioners require skills to

17 provide one-to-one coach support and group-based interventions. All practitioners

18 perceived that training programmes do not adequately equip trainees with skills required

19 for coach work. We discuss the implications for enhancing practitioner training in the

20 UK.

21

22 Key words: sport coaches, psychological support, content analysis, applied sport

23 psychology. 
PSYCHOLOGICAL SUPPORT TO COACHES

3 Sport coaches are required to manage athlete and team performances whilst maintaining

4 their own psychological well-being, and can arguably be construed as performers in

5 their own right (Thelwell, Weston, Greenlees, \& Hutchings, 2008). Recognising coach

6 job demands and the psychological skills required of coaches to manage their demands

7 and stressors has implications not only for coaches, but also the athletes they support

8 (Thelwell, Wagstaff, Chapman, \& Kenttä, 2017). It is also the case that athletes

9 recognise stress within their coaches through coach behaviours, appearance and
Psychological Support for Sport Coaches: An Exploration of Practitioner

\section{Psychologist Perspectives.}

Rayner, Chapman, \& Barker, 2017).

Given the demands placed on sport coaches, it is plausible to suggest that psychologists are ideally placed to support coaches to enable them to recognise the effects of stress on their coaching effectiveness. This very point is evidenced within empirical studies where coaches have reported the use of psychologists to support their psychological preparation for Olympic competition (e.g., Gould, Greenleaf, Guinan, \& Chung, 2002) and to manage other psychological challenges that include stress and emotion management (e.g., Thelwell et al, 2017). Furthermore, effective coachpsychologist relationships have been found to develop when coaches' perceive the psychologist has sufficient knowledge to provide support, and when they are seen to fit in with the team (Sharp \& Hodge, 2013). Although these findings provide initial information about how psychologists might be perceived by coaches, they do not draw together psychologist narratives about their experience of coach work, or psychologist views about the (psychological) needs of coaches and the skills required to meet these needs. 


\section{PSYCHOLOGICAL SUPPORT TO COACHES}

The British Psychological Society (BPS) professional training route for Sport and Exercise Psychologists (the Qualification in Sport and Exercise Psychology grants eligibility for practitioner psychologist status with the HCPC) but does not stipulate any specific competencies required to work with sports coaches. This is a pertinent concern given that coaches are dignitaries with athletes and teams across all sport environments, from grassroots level to elite standard environments, and psychologists are likely to be required to work with coaches within applied practice. Thus, it is feasible to speculate that practitioner psychologists do not acquire the skills to carry out psychological work with coaches through learning about evidence-based approaches, but rather through chance experiences. In fact, although the QSEP is positioned to be a professional development process, one might question the degree to which it fully enables a training process consistent with Miller's (1990) 'gold standard’ pyramid of clinical competence, e.g., where trainees progress through stages of having knowledge, to knowing how to apply that knowledge, through to being able to competently apply knowledge into practice to develop professional authenticity. This contradicts the notion of sport psychology being an evidence-based discipline that is guided by scientific knowledge gained through research, theory and practice to influence psychological change. Therefore, exploring psychologist perspectives about the training requirements to how practitioners could and should develop skills to deliver support to coaches is worthy of exploration.

The overall purpose of this study was to make a substantive contribution to the literature about the skill requirements of practitioner psychologists for coach work. To fulfil this purpose, we proposed four aims. First, to explore practitioners understanding of the challenges sport coaches face within the coach role. Second, to gain practitioner reports about type of support they provide, or have provided, to sport coaches. Third, to understand practitioner perspectives about ways in which psychologists could and 


\section{PSYCHOLOGICAL SUPPORT TO COACHES}

1 should support sport coaches. Finally, to ascertain views about how current professional

2 training programmes equip practitioners with knowledge and skills for coach work.

\section{Method}

4 We used a qualitative design using semi structured interview methods. A purposive

5 sample comprising 10 practitioners (seven qualified, three trainees) were recruited over

6 a period of three months. Participants filled inclusion criteria in that they reported

7 themselves to be either registered HCPC practitioner psychologists (i.e., legally able to

8 label themselves as a Practitioner Psychologist), or as Trainee Sport and Exercise

9 Psychologists on the BPS QSEP (that confers membership of the Division of Sport and

10 Exercise Psychology within the BPS, and registration to the HCPC).

Seven males and three female participants were interviewed, with an age range spanning 26 to 56 years $($ Mage $=38.8, S D=9.33)$. All participants reported having prior applied experience of work with coaches across all performance domains.

14 Participants applied experience of working with sport coaches ranged from 2.5 years to 1527 years $($ Myears $=12.6, S D=9.45)$. All participants rated their experience of working 16 with coaches on a scale of 1-10 (where 10 indicated highly experienced and 1 no 17 experience at all). Participant ratings on this scale ranged from $4-9$ (Mexperience $=$ $18 \quad 6.8, S D=1.4)$.

****Table 1 near here*****

\section{Interview schedule}

The development of the interview schedule followed a review of research which examined athletes' perceptions of coach stress in elite sport environments (Thelwell et 25 al., 2016) and also drew on evidence around effective coach-psychologist relationships (Sharp \& Hodge, 2013). The schedule was piloted with a practitioner psychologist prior 


\section{PSYCHOLOGICAL SUPPORT TO COACHES}

1 to data collection. Feedback recommended that the schedule might benefit from

2 considering participants experiences of working as a coach prior to their psychology

3 career. No other amendments were suggested. A final interview schedule comprising

4 four sections was used: (1) practitioner understanding of the challenges of the sport

5 coach role, (2) understanding how practitioners have gained entry to work with sports

6 coaches and what type of work was completed, (3) understanding how a practitioner

7 perceives they should and could support a coach across the varying levels and finally,

8 (4) current professional training opportunities for work with coaches.

\section{Data collection}

Having received university ethical approval, participants were approached by

11 email. Each participant was provided with an information sheet and given time to

12 consider study participation. Participants were reassured they could withdraw from the

13 study up until interview transcription. Interviews were carried out by the lead

14 researcher, an active listener who encouraged participants to tell their stories in their

15 own words. The lead researcher was a Clinical Psychologist trained to use qualitative

16 methods through doctorate level training.

17 Participants were offered face to face, Skype or telephone interviews. This

18 resulted in nine interviews being carried out by Skype and one by telephone. Individual

19 interview times ranged from 41 minutes to 68 minutes (Mtime $=51.47, S D=7.83$ ),

20 yielding a total of 131 pages of text. All interviews were transcribed verbatim by the

21 lead researcher. Participants were guided through an identical set of questions to ensure

22 structure to each interview. Prompts and probes were employed (e.g., "what was it

23 about [the issue] that led to...?” and elaboration, "could you elaborate on [the issue]

24 please?”) to ensure all issues were investigated in depth. 


\section{PSYCHOLOGICAL SUPPORT TO COACHES}

Once the interview had been transcribed they were returned to the participant to

2 check for accuracy. Having agreed the transcripts' accuracy, the data were then

3 analysed.

\section{$4 \quad$ Data analysis}

The data were analysed using the recommendations of Connelly and Peltzer

6 (2016). To achieve this, the first and second researchers read and reread interview

7 transcripts prior to content analysing each transcript. Words, phrases and quotes arising

8 from transcripts were then independently identified and coded. A third researcher then

9 reviewed the data collated and verified phrases, quotes and data themes. Following

10 agreement between the three researchers, raw-data themes were then organized into

11 groups of common themes (higher order themes), which resulted in the emergence of

12 general dimensions, where above this, no further meaning could be identified.

The content analysis adopted an inductive stance; however comparisons with

14 themes from previous research and existing labels from the literature were considered

15 when similarities arose. In the latter stages of the data analysis themes were deductively

16 placed into post hoc categories, based on emerging themes. Having used both inductive

17 and deductive analyses to interpret the data into higher order themes and general

18 dimensions (Biddle, Markland, Gilbourne, Chatzisarantis, \& Sparkes, 2001), the final

19 phase of analysis involved gaining triangular consensus between the lead, second, and

20 third researcher along with an additional researcher who acted as a "critical friend"

21 (Faulkner \& Biddle, 2002). The additional researcher was not involved with the data

22 collection or analysis and was required to confirm, or otherwise, the placement of raw

23 data themes into general dimensions.

\section{Enhancing the trustworthiness of the analysis}




\section{PSYCHOLOGICAL SUPPORT TO COACHES}

Using guidelines relating to qualitative methods recommended by Sparkes and

2 Smith (2009) and Tracy (2010), checks were made to ensure eight criteria (worthy

3 topic, rich rigour, sincerity, credibility, resonance, significant contribution, ethics and

4 meaningful coherence) were met. Exploring psychologist perspectives about skill

5 requirements for coach work was perceived to be a worthy topic. With regards rich

6 rigour, all participants were asked to confirm the content of their interview script prior

7 to data analysis, encouraged to add additional material, and provided with verbal and

8 written debrief. Sincerity was observed via the critical friend who confirmed accuracy

9 in the tracking of the data to interview transcripts, and ensured agreement between three

10 researchers about lower order and higher order themes. This helped maximise the

11 trustworthiness of the analysis process. To ensure credibility, we ensured that emergent

12 themes were logically traced back to participant quotations. Furthermore, we

13 highlighted direct quotations to support findings, which we argue demonstrated

14 resonance in that it allowed for visual representations of participants experiences. In

15 terms of contributing to the literature, we argue the study has theoretical (e.g.,

16 conceptual understanding), heuristic (e.g., stimulation of curiosity and further

17 investigation) and practical (e.g., professional training programmes and applied

18 practice) implications that develop this area of study. Institutional ethical clearance was

19 obtained. Situational (e.g., the keeping of a reflexive diary by the lead researcher to

20 capture the analysis process and reflect on data worth exposing), relational (e.g.,

21 reflection on researcher actions and potential consequences of data analysis) and exiting

22 (e.g., avoiding unjust or unintended consequences of findings presented) obligations

23 were also adhered to. Finally, in terms of meaningful adherence, the study used

24 methods consistent with and comparable to earlier studies of coach stress in elite sport

25 environments and studies of coach-psychologist relationships. 
PSYCHOLOGICAL SUPPORT TO COACHES

\section{Results}

Results derived from content analysis represented the collated narratives of all

310 participants. Raw data themes were categorised into lower and then higher order

4 themes before being organised according to the four study aims: understanding of the

5 challenges coaches face within their coach role; experience of coach work; views about

6 ways that psychologists could and should support coaches across varying levels and,

7 fourthly, views about the degree to which professional training programmes equip

8 practitioners with knowledge and skills for coach work. We present data in Figures 1-4

9 and through the following narrative.

10 Practitioner understanding of the challenges faced by sports coaches

Practitioners' understanding of the challenges faced by sports coaches is shown

12 in Figure 1.

A total of 40 raw data themes were inductively placed into nine lower order

15 themes and 5 higher-order themes. The roles of a sport coach working at a grassroots

16 level were viewed most commonly in terms of nurturing athletes psychosocial

17 development, namely to ensure “enjoyment and fun”, “to keep athletes participating”,

18 and "to build up (athlete) self-esteem”. In contrast, coach roles with elite athletes

19 centred on "performance outcomes", with maintaining a "performance focus”, and

20 "results" being most commonly cited. One participant described, "Performance coach

21 roles are performance based, so their roles are much more focused on competitive

22 preparation". This finding suggests that practitioners believe the sport coach role varies

23 across the varying levels of performance. 


\section{PSYCHOLOGICAL SUPPORT TO COACHES}

Further to roles being perceived differently according to level of performance

2 environment, raw data themes emerged about the different challenges faced by coaches

3 across the varying levels. With regards elite level coaches, challenges associated with

4 performance stressors, namely athlete performance and ensuring results were most

5 commonly cited, followed by organisation stressors relating to leadership and

6 management. In contrast, at the grassroots level, performance stressors around meeting

7 athletes' developmental and psychosocial needs were most common. This data indicates

8 practitioners perceive that coaches working in elite environments face challenges

9 centred on athlete performance outcomes and organisation stressors around leadership,

10 whereas the challenges for grassroots level coaches' centre on ensuring athletes keep

11 participating in the sport.

12 Practitioner experiences of coach work

The full range of participant reports regarding support provided to sport coaches

14 irrespective of performance domain is summarised in Figure 2.

21 raw data themes were inductively placed into five lower order themes and

17 two higher-order themes. Providing support to the coach about creating conducive

training and competition environments was most commonly cited, for example in

19 supporting the coach to create an "enjoyable player environment", and in creating

20 "team mindset". This point is highlighted in the following extract:

I'll probably be around the training environment, to try and get a feel for that, to 


\section{PSYCHOLOGICAL SUPPORT TO COACHES}

3 Further to the above, providing support to coaches around their well-being also emerged

4 as a theme. The following excerpt details a participant's experience of supporting an

5 elite coach with their well-being:

I've done work with one coach particularly, a lot of work on stuff that's being going on in his private life he's been struggling to deal with which we've done work around because he doesn’t wanna, obviously kind of let it affect his coaching and perhaps the players, so that's been a key role really.

In terms of other formal support provided specifically to coaches, the psychologist as a facilitator of effective coach-parent relationships emerged, as evidenced in the following narrative:

Parent workshops bridge a gap. We need to get the parents to reinforce coach messages, and I can do that by facilitating communication of coach goals to parents. My experience is that they (parents) don’t understand why coaches do certain things.

As well as formal support, providing informal support to coaches also presented as a higher order theme which encompassed giving "general advice,” to coach about coaching ideas and providing informal check-ins about general coaching demands. This finding suggests practitioners perceive providing psychological support to coaches encompasses both formal and informal work, the effectiveness of which depends on working relationships between coach, psychologist and parents.

\section{Practitioner views about how they can be of benefit to sport coaches}




\section{PSYCHOLOGICAL SUPPORT TO COACHES}

Data collated about the various ways participants perceived they should and

2 could potentially support sport coaches is summarised in Figure 3.

3

***Figure 3 near here ${ }^{* * * *}$

A total of 20 raw data themes were inductively placed into six lower order themes and three higher order themes. The most commonly reported way that psychologists perceived they should and could provide psychological support to elite coaches was through "confidential support”. The following quotation highlights one practitioner's perspective:

by being a skilled sounding board, or using some kind of counselling approach, where there’s intense focused dialogue relating to performance and wellbeing, managing the board and staff, and doing that to help the coach deal with the challenges that they've got as a coach, as a performer. That's huge.

At grassroots level, provision of education and training was most commonly cited, specifically psychologists providing education around psychological skills (for example, goal setting, mental skills, concentration), and psychosocial skills (for example, self-esteem, motivation, enjoyment). The following quotation highlights one practitioner’s perspective: “I can definitely see a massive benefit in (psychology) delivering workshops at grassroots level on key things like motivation, enjoyment, achievement goals, those kind of things”.

A further role centred on helping a coach both understand players and communicate effectively with players was also reported. One participant said, "Psychologists should be helping them (coaches) to understand players, helping them to understand certain personality types so that they can better manage them”. 


\section{PSYCHOLOGICAL SUPPORT TO COACHES}

To complete the range of roles that practitioners could or should involve

2 themselves in terms of coach work, a higher order theme of "team

3 culture/environment”, was identified, specifically working with coaches to create

4 conducive training environments. With specific reference to coaches working at the elite

5 level, participants also reported providing support to coaches around competition

6 preparation, as well as training practices. For example, developing team cohesion in the

7 lead up to a competition, ensuring athletes have clearly defined roles/responsibilities,

8 and in ensuring coaches are equipped with skills to cope in pressured competitive

9 situations.

10 Degree to which professional training programmes equip practitioners with

\section{1 knowledge and skills for coach work}

The full range of responses regarding the degree to which professional training

13 prepares for coach work is illustrated in Figure 4.

****Figure 4 near here ${ }^{* * * *}$

A total of 23 raw data themes were inductively placed into seven lower order themes and three higher order themes, namely "preparation positive”, "preparation

17 negative”, and “improvements for training programmes”. From both qualified and trainee perspectives, a lower order theme of “CPD”, namely supervision, workshops

19 and conferences were most commonly cited within the "preparation positive",

20 dimension. With regards to "preparation negative”, lower order themes relating to

21 “applied experience”, during practitioner training were most commonly reported. One

22 qualified practitioner discussed her experience: “It didn’t. I didn’t have any contact with

23 coaches during my training”. In terms of exposure through supervision, she said: “He

24 (supervisor) didn't expose me to any coaches because that's not what he did". These 


\section{PSYCHOLOGICAL SUPPORT TO COACHES}

1 findings suggest supervision is perceived as important, but that opportunity to gain

2 applied supervised experience of coach work is limited. This is perhaps unsurprising

3 given that there is nothing explicit within the current accreditation process to how

4 practitioners should, or could, work with sports coaches.

In terms of how professional training might better support coach work, a need

6 for training programmes to make coach work mandatory within the accreditation

7 process was most commonly reported, and to ensure that supervisors encourage coach

8 work. This was highlighted in one participant's narrative:

I think the supervisor has a huge role to play here and the supervisor needs to guide the stage two candidate towards developing that knowledge set and the skill set to engage and work with and through coaches and I don't think that's a priority in the documentation, but I think it can become a priority within the supervisory process.

Further to this, comments about getting coaches actively involved with training courses were raised. One qualified practitioner commented, “I think they (training courses) should run workshops where they get coaches in and get coaches running a workshop in terms of I'm in a head coach position and this is what I'd like to see from a psychologist”. These findings suggest practitioners perceive coaches should be empowered to actively contribute to professional training curriculums.

\section{Discussion}

In this study we explored the degree to which practitioner psychologists perceive themselves able to support sport coaches and the skill requirements of practitioners for working with coaches. To this end, data provide valuable progression in the literature. We have systematically examined practitioner views about the challenges coaches face 


\section{PSYCHOLOGICAL SUPPORT TO COACHES} 4 (with particular reference to the UK).

within their job and identified ways in which practitioners can potentially support coaches. Furthermore, we have identified how current practitioner psychologist training courses should equip practitioners with the skills required for working with coaches

In this study we found that practitioners view the sport coach role, and challenges faced within that role, are different for coaches working at a grassroots level compared to coaches working within an elite environment, e.g, meeting athletes psychosocial needs at grassroot level, in contrast to ensuring performance and results at elite level. Practitioners also perceived they could benefit coaches in different ways across the varying levels through providing group based education to coaches centred on psychological skills training at the grassroots level, to one to one work that draws on counselling based approaches at the elite level. This finding also supports earlier studies that have suggested providing confidential support to coaches on a one-to-one basis within elite environments is integral to the psychologists' role (Eubank, Nesti, \& Cruickshank, 2014). Our present study also extends on earlier findings by providing evidence as to how practitioners perceive they can provide support to coaches operating at the grassroots level too. This has ramifications in terms of how professional training courses equip practitioners with sufficient skill-sets to work with the complexity of coach roles that differ across performance domains.

With regards to current psychological support provision to coaches, our data highlights that practitioners often provide informal advice to coaches around general coaching demands, and that within this, practitioners provide advice on managing personal issues effecting their coaching ability. This finding is consistent with previous research which has suggested psychologists should be trained to apply principles derived from counselling psychology domains, to encourage coaches to understand and 


\section{PSYCHOLOGICAL SUPPORT TO COACHES}

2 al., 2004; McCarthy \& Giges, 2017). Our data also indicates that professional training

3 programmes may benefit from exposing trainees to a broader range of psychological

4 theories and concepts that go beyond sport psychology (e.g., learning about counselling

5 and clinical psychology models), to equip trainees for coach work.

Regarding the degree to which professional training prepares psychologists to work with coaches, findings were consistent with Sharp and Hodge (2011) who also found supervision to be critical for sport psychologists, and also with evidence that psychologists view self-reflection as a crucial means of helping them to understand their self as a person and practitioner (Pack, Hemmings, \& Arvinen-Barrow, 2014).

The finding that opportunities to gain applied supervised experience and observe psychological work with coaches are limited is perhaps unsurprising given that there is nothing explicit within the current accreditation process to how practitioners should, or could, work with sports coaches. The implication for professional training programmes is thus a need to bridge the gap between theory and practice, where supervisors expose trainees to applied environments and provide opportunities to both observe and be observed carrying out psychological work with coaches.

With regards to improving current professional training programmes, practitioners reported coaches should be empowered to voice their expectations of psychological support through training curriculums. This has implications in terms of how such empowerment might be facilitated, for example, through involving coaches in the interviewing of candidates as part of the recruitment process onto professional training courses. This could benefit from exploration in future work. 


\section{PSYCHOLOGICAL SUPPORT TO COACHES}

Despite our attempts to explore a worthwhile area within applied sport

2 psychology a number of limitations exist. First, the retrospective design of the interview

3 design involved collecting data from fully qualified practitioners about their experience

4 of professional training several years ago. Thus, the preciseness in recall of events and

5 potential for memory bias must be considered. Second, practitioner experiences of

6 working with coaches ranged from providing psychological support within an

7 individual sport, team sports and within academia. Indeed, our design allowed for broad

8 range of experiences to be captured. However, if the sample had been bigger, it may

9 have been worth segregating results even further to highlight different perspectives.

A priority for future researchers is to explore coach perspectives about

11 psychological support. For example, coach reasons for accessing or not accessing

12 psychological support and coach views on how psychological support might best be

13 offered are appropriate avenues for researchers. Such research would allow for a

14 comparison of results generated from this study and further the development of evidence-based psychological interventions that meet the needs of coaches.

In conclusion, we have revealed that practitioner psychologists perceive sport

17 coaches working across all levels of performance are exposed to varying performance and organisational related demands and stressors that may benefit from psychological support. However, practitioners perceive that the demands and stressors placed on

20 coaches vary according to the level of performance environment a coach operates

21 within, and as such different skill sets are required of psychologists. All practitioners

22 perceived that professional training programmes do not adequately equip trainee

23 practitioners with the skills required to do such work, and that the training of

24 psychologists with reference to coach demands is limited at best. Furthermore, findings

25 have implications for current UK professional training programmes for psychologists, 


\section{PSYCHOLOGICAL SUPPORT TO COACHES}

1 namely that more proactive work needs to be done that focuses on equipping trainees

2 with skills to work with coaches across the varying levels. Our data suggest that this

3 could be addressed through better-defined training course curriculums that make

4 reference to coach work, supervised opportunities for trainees to experience coach

5 work, and through actively involving sports coaches in professional training

6 curriculums. 
PSYCHOLOGICAL SUPPORT TO COACHES

\section{References}

Altfeld, S., \& Kellmann, M. (2013). Burnout in coaches. In B.R. Doolittle (Ed.), Psychology of burnout: New research, (pp 193-207). NY: Nova Science Publishers.

Arnold, R., Fletcher, D., \& Molyneux, L. (2012). Performance leadership and management in elite sport: Recommendations, advice and suggestions from national performance directors. European Sport Management Quarterly, 12, 317-336. doi:10.1080/16184742.2012.693115

Barker, S., \& Winter, S. (2014). The practice of sport psychology: A youth coach perspective. International Journal of Sport Science and Coaching, 9(2), 379392.

Biddle, S. J., Markland, D., Gilbourne, D., Chatzisarantis, N. L., \& Sparkes, A. C. (2001). Research methods in sport and exercise psychology: quantitative and qualitative issues. Journal of Sports Sciences, 19(10), 777-809.

Brady, A., \& Maynard, I. (2010). At an elite level the role of a sport psychologist is entirely about performance enhancement. Sport \& Exercise Psychology Review, 6(1), 59-66.

British Psychological Society (2014). Code of Human Research and Ethics. Leicester: The British Psychological Society.

British Psychological Society (2009) Code of ethics and conduct. Leicester: The British Psychological Society.

Connelly, L., \& Peltzer, J. N. (2016). Underdeveloped themes in qualitative research: Relationship with interviews and analysis. Clinical Nurse Specialist, 30, 52-57.

Côté, J., Salmela, J. H., Baria, A., \& Russell, S. J. (1993). Organizing and 
PSYCHOLOGICAL SUPPORT TO COACHES

Interpreting unstructured qualitative data. The Sport Psychologist, 2, 127-137.

Cruickshank, A., \& Collins, D. (2013). Culture change in elite sport performance: An important and unique construct. Sport and Exercise Psychology Review, 9 (2), 621.

Eubank, M., Nesti, M., \& Cruickshank, A. (2014). Understanding high performance sport environments: impact for the professional training and supervision of sport psychologists. Sport \& Exercise Psychology Review, 10(2), 30-36.

Faulkner, G., \& Biddle, S. J. H. (2002). Mental health nursing and the promotion of physical activity. Journal of Psychiatric and Mental Health Nursing, 9, 659-665.

Fletcher, D., Hanton, S., \& Mellalieu, S. D. (2006). An organizational stress review: Conceptual and theoretical issues in competitive sport. In S. Hanton \& S. D. Mellalieu (Eds.), Literature reviews in sport psychology (pp. 321-373). Hauppauge, NY: Nova Science.

Gearity, B. T. \& Murray, M. (2011). Athletes’ experiences of the psychological effects of poor coaching. Psychology of Sport and Exercise, 12, 213-221

Giges, B., Petitpas, A. J ., \& Vernacchia, R. A. (2004). Helping coaches meet their own needs: Challenges for the sport psychology consultant. The Sport Psychologist, 18(4), 430-44.

Gould, D., Greenleaf, C., Guinan, D., \& Chung, Y. (2002). A survey of U.S. Olympic coaches: Variables perceived to have influenced athlete performances and coach effectiveness. The Sport Psychologist, 16(3), 229-250.

Hanton, S., Fletcher, D., \& Coughlan, G. (2005). Stress in elite performers: A comparative study of competitive and organizational stressors. Journal of Sports Sciences, 23(10), 1129-1141. 


\section{PSYCHOLOGICAL SUPPORT TO COACHES}

1 Harwood, C. G., Barker, J. B., \& Anderson, R. (2015). Psychosocial development inyouth soccer players: Assessing the effectiveness of the 5Cs intervention program. The Sport Psychologist, 29(4), 319-334.

McCarthy, P., \& Giges, B. (2017). Helping coaches meet their psychological needs. In R.C. Thelwell, C, Harwood, and I.A. Greenlees (Eds.), The psychology of sports coaching: Research and Practice. Oxford, U.K.: Routledge.

Miles, M. B., \& Huberman, A. M. (1994). Qualitative Data Analysis (2nd edition). Thousand Oaks, CA: Sage Publications.

Miller, G. E. (1990). The assessment of clinical skills, competence and performance. Academic Medicine 65(1), 63-67.

Nesti, M. (2010). Psychology in football: Working with elite and professional players. London: Routledge.

Olusoga, P., Maynard, I., Hays, K., \& Butt, J. (2012). Coaching under pressure: A study of Olympic coaches. Journal of Sport Sciences, 30(3), 229-239.

Pack, S., Hemmings, B., \& Arvinen-Barrow (2014). The self-practice of sport psychologists: Do they practice what they preach?. The Sport Psychologist, 28(2), 198-210.

Sharp, L. A., \& Hodge, K. (2013). Effective sport psychology consulting relationships: Two coach case studies. The Sport Psychologist, 27(4), 313-324.

Sparkes, A. C., \& Smith, B. (2009). Judging the quality of qualitative inquiry: criteriology and relativism in action. Psychology of Sport and Exercise, 10, 491497.

Stebbings, J., Taylor, I. M., \& Spray, C. M. (2015). The relationship between psychological well- and ill-being, and perceived autonomy supportive and controlling interpersonal styles: A longitudinal study of sport coaches. Psychology of Sport and Exercise, 19(1), 42-29. 


\section{PSYCHOLOGICAL SUPPORT TO COACHES}

1 Thelwell, R.C., Wagstaff, C.R.D., Rayner, A., Chapman, M., \& Barker, J. (2017). Exploring athletes' perceptions of coach stress in elite sport environments. Journal of Sports Sciences, 35, 44-55. DOI: 10.1080/02640414.2016.1154979

4 Thelwell, R. C., Weston, N. J. V., Greenlees, I. A., \& Hutchings, N. V. (2008).

5 Stressors in elite sport: A coach perspective. Journal of Sports Sciences, 26(9), 6 905-918.

7 Thelwell, R. C., Wagstaff, C. R. D., Chapman, M., \& Kentta, G. (2017). Examining coaches’ perceptions of how their stress influences the coach-athlete relationship. Journal of Sports Sciences. DOI:

11 Tracy, S. J. (2010). Qualitative quality: Eight “big tent” criteria for excellent qualitative research. Qualitative Inquiry, 16, 837-851. 
PSYCHOLOGICAL SUPPORT TO COACHES

\section{Table captions}

2 Table 1. Demographic characteristics of the 10 participants

\section{$3 \quad$ Figure captions}

$4 \quad$ Figure 1. Practitioner understanding of the challenges faced by a sports coach (numbers

5 in parentheses illustrate the number of participants citing the source when $>1$ )

$6 \quad$ Figure 2. Gaining of entry to work with sport coaches and support provided (numbers

7 in parentheses illustrate the number of participants citing the source when $>1$ )

8 Figure 3. Practitioner views about ways of supporting sport coaches across varying

9 levels (numbers in parentheses illustrate the number of participants citing the source

10 when $>1)$

11 Figure 4. Degree to which practitioners perceive that professional training prepares

12 psychologists to work with sports coaches (numbers in parentheses illustrate the number

13 of participants citing the source when $>1$ ) 